\title{
DUKUNGAN KELUARGA MEMENGARUHI KEPATUHAN PASIEN HIPERTENSI
}

\author{
Fitra Yeni ${ }^{1 *}$, Miftahul Husna ${ }^{1}$, Dachriyanus ${ }^{2}$ \\ 1. Fakultas Keperawatan Universitas Andalas, Padang 25163, Indonesia \\ 2. Fakultas Farmasi Universitas Andalas, Padang 25163, Indonesia \\ *E-mail: fitra.yeni@rocketmail.com
}

\begin{abstract}
Abstrak
Hipertensi adalah keadaan meningkatnya tekanan darah sistolik lebih besar dari $140 \mathrm{mmHg}$ dan atau diastolik lebih besar dari $90 \mathrm{mmHg}$. Keefektifan terapi pasien hipertensi ditentukan oleh kepatuhan, dan dukungan keluarga dapat menjadi faktor yang sangat berpengaruh. Penelitian ini bertujuan untuk membuktikan seberapa besar hubungan dukungan keluarga dengan kepatuhan pada pasien hipertensi. Ini merupakan penelitan deskriptif korelatif dengan pendekatan cross sectional dan jumlah sampel sebanyak 59 orang. Pengumpulan data dilakukan di Puskesmas Padang Pasir Kota Padang tanggal 4-30 April 2013 dengan menggunakan kuesioner. Analisa data penelitian terdiri dari analisa univariat yang menggambarkan dukungan keluarga dan kepatuhan responden sedangkan analisa bivariat menggunakan uji korelasi Rank Spearman (r). Hasil penelitian menunjukkan sebanyak 54\% responden mendapatkan dukungan keluarga dengan kategori sedang dan 59\% responden mempunyai kepatuhan dengan kategori sedang. Hasil uji statistik didapatkan nilai $(\mathrm{r})=0,786$. Disimpulkan bahwa dukungan keluarga mempunyai hubungan sangat kuat dengan kepatuhan dan terdapat hubungan searah, sehingga semakin tinggi dukungan keluarga maka semakin tinggi kepatuhan. Dukungan keluarga berkontribusi sebesar $61,8 \%$ terhadap kepatuhan. Keluarga harus lebih memperhatikan pemberian dukungan informasional terhadap pasien hipertensi.
\end{abstract}

Kata kunci: dukungan keluarga, hipertensi, kepatuhan

\begin{abstract}
Family Support Affect Patient Compliance with Hypertension. Hypertension is a state of increased systolic blood pressure greater than $140 \mathrm{mmHg}$ and or diastolic greater than $90 \mathrm{mmHg}$. The effectiveness of treatment is determined by the compliance of hypertensive patients, and family support can be a very influential factor. This study aims to determine the relationship of family support with adherence in hypertensive patients. The study was a descriptive correlative with cross sectional approach and sample are 59 people. Data collection was conducted at Puskesmas Padang Pasir from 4 to 30 April 2013, collected using questionnaires. Data analysis consisted of univariate analysis that describes the family support and adherence respondents then bivariate analysis using Rank Spearman ( $r$ ) correlation test. The results showed $54 \%$ of respondents have family support with medium category and 59\% respondents have compliance with medium category. Statistical test results obtained values $(r)=0.786$. Concluded that family support has a very strong relationship with compliance and there is a direct relationship, so higher family support make impact higher compliance. Family support accounted for $61.8 \%$ of compliance. Family should pay more attention to providing informational support to patients with hypertension
\end{abstract}

Keywords: adherence, family support, hypertension

\section{Pendahuluan}

Di dunia, Penyakit Tidak Menular (PTM) telah menyumbang 3 juta kematian pada tahun 2005 di mana $60 \%$ kematian diantaranya terjadi pada penduduk berumur di bawah 70 tahun. Penyakit tidak menular yang cukup banyak memengaruhi angka kesakitan dan angka kematian dunia adalah Penyakit Kardiovaskuler (PKV). Penyakit Kardiovaskuler yang 
memengaruhi angka kesakitan dan kematian di dunia adalah hipertensi.

Hipertensi adalah keadaan meningkatnya tekanan darah sistolik lebih besar dari $140 \mathrm{mmHg}$ dan atau diastolik lebih besar dari $90 \mathrm{mmHg}$ pada dua kali pengukuran dengan selang waktu 5 menit dalam keadaan cukup istirahat atau tenang (Kemenkes, 2010). Satu dari tiga orang dewasa di seluruh dunia teridentifikasi mengalami peningkatan tekanan darah suatu kondisi yang menyebabkan sekitar setengah dari semua kematian akibat stroke dan penyakit jantung (WHO, Health Statistic Report, 2012). Secara global, prevalensi keseluruhan naiknya tekanan darah pada orang dewasa berusia 25 tahun ke atas adalah sekitar $40 \%$ pada tahun 2008. Pada tahun 2011, hipertensi telah menyumbangkan kematian sebesar 38\% dari seluruh kematian yang terjadi di kawasan Asia Tenggara. Sementara itu, di Indonesia prevalensi hipertensi adalah sebesar 30,9\% pada tahun 2008 (WHO, 2013).

Penanganan pada pasien hipertensi diantaranya terapi pengobatan dan pengaturan makanan serta gaya hidup (Yayasan Jantung Indonesia, 2006). Keefektifan penanganan berkelanjutan atau terapi ditentukan oleh kepatuhan. Berbagai studi mengungkapkan bahwa tingkat kepatuhan minum obat pada penderita hipertensi hanya berkisar antara 50-60\% (Almas A. dkk, 2006). Rendahnya tingkat kepatuhan pasien pada terapi penyakit hipertensi ini dapat memberikan efek negatif yang sangat besar (Kemenkes, 2010).

Dalam melakukan terapi, keluarga dapat menjadi faktor yang sangat berpengaruh dalam program pengobatan tekanan darah. Bimbingan penyuluh dan dorongan secara terus-menerus biasanya diperlukan agar penderita hipertensi tersebut mampu melaksanakan rencana yang dapat diterima untuk bertahan hidup dengan hipertensi dan mematuhi aturan terapinya (Smetzer, 2001). Pada penelitian ini dibahas mengenai hubungan dukungan keluarga dengan kepatuhan pada pasien hipertensi, dimana kepatuhan tersebut meliputi kepatuhan minum obat, diet, berolahraga dan mengelola stress. Sehingga variabel pada penelitian ini akan dibahas secara mendetail.

Berdasarkan hasil rekapitulasi Dinas Kesehatan Kota Padang tahun 2012 dari 20 Puskesmas yang ada di Kota Padang menunjukkan jumlah penderita hipertensi sebanyak 36.654 orang dan kunjungan terbanyak terdapat di Puskesmas Padang Pasir (Dinas Kesehatan Kota Padang, 2012). Dari hasil studi pendahuluan yang dilakukan oleh peneliti di Puskesmas Padang Pasir pada tanggal 20 Februari 2013 dari 10 orang penderita hipertensi yang melakukan kunjungan, 4 (empat) diantaranya mengaku tidak teratur menjalani terapi obat karena lupa dengan jadwal minum obat dan keluarga tidak mengingatkan, serta tidak nyaman dengan efek samping obat. Sedangkan 6 (enam) orang lainnya mengatakan minum obat secara teratur karena didukung oleh keluarga, namun jarang berolahraga. Berdasarkan latar belakang di atas, maka peneliti merumuskan masalah penelitian ini apakah ada hubungan dukungan keluarga dengan kepatuhan pada pasien hipertensi di Puskesmas Padang Pasir tahun 2013.

\section{Metode}

Desain penelitian merupakan bentuk rancangan yang akan digunakan dalam melakukan prosedur penelitian. Penelitian ini merupakan penelitian kuantitatif, dalam penelitian yang akan dilakukan peneliti menggunakan rancangan deskriptif-korelatif dengan metode penelitian cross-sectional.

Instrumen yang digunakan dalam penelitian ini dalam bentuk kuesioner kepada responden dengan menggunakan skala likert. Untuk kuesioner, responden diminta untuk memberi tanda $(\sqrt{ })$ pada kolom yang ditentukan. Instrumen dukungan keluarga memiliki 20 butir pernyataan dan instrumen kepatuhan memiliki 20 butir pernyataan. 
Untuk instrumen dukungan keluarga dan kepatuhan masing-masing memiliki 20 butir pernyataan, yang setiap pernyataan positif diberi skor 1 untuk jawaban tidak pernah, 2 untuk jawaban jarang, 3 untuk jawaban sering dan 4 untuk jawaban selalu. Sebaliknya untuk pernyataan negatif diberi skor 4 untuk jawaban tidak pernah, 3 untuk jawaban jarang, 2 untuk jawaban sering dan 1 untuk jawaban selalu.

Skala yang digunakan dalam penelitian ini dibagi menjadi tiga kelompok pada masingmasing variabel, yaitu tinggi, sedang dan rendah. Pengkategorian kelompok dengan menggunakan rumus berdasarkan data mean dan standar deviasi dalam menentukan cut of point. Data diolah menggunakan SPSS for windows.

Analisa univariat digunakan untuk mengetahui distribusi dan uji statistik dari setiap variabel yang diteliti. Menurut Azwar (2010) sebagai suatu hasil ukur berupa angka (kuantitatif), skor skala memerlukan suatu norma pembanding agar dapat diinterpretasikan secara kualitatif. Subjek dapat dikategorisasikan dalam tiga kategori, menjadi tinggi, sedang dan rendah.

Analisa bivariat menggunakan uji korelasi Rank Spearman (r) untuk melihat kekuatan hubungan dan arah antara dua variabel. Sebelum dilakukan uji korelasi Spearman (r), dilakukan uji normalitas terlebih dahulu dan didapatkan hasil data tidak berdistribusi normal. Untuk mengetahui seberapa besar kontribusi atau sumbangan dukungan keluarga terhadap kepatuhan dicari menggunakan koefisien determinasi atau koefisien determinan. Menurut Sugiyono (2006) untuk mengetahui nilai koefisien determinasi, maka dapat dihitung dengan menggunakan rumus :

$$
\mathrm{KD}=\mathrm{r}^{2} \times 100 \%
$$

Keterangan :

$\mathrm{KD}=$ Koefisien Determinasi

$r \quad=$ Kuadrat Koefisien Korelasi
Sebelum melakukan penelitian, peneliti mengajukan permohonan izin ke Puskesmas Padang Pasir. Setelah mendapatkan persetujuan, peneliti mulai melakukan penelitian dengan memerhatikan masalah etika yang meliputi: inform consent, anonymity dan confidentiality.

\section{Hasil}

Jumlah responden adalah 59 orang yang memenuhi kriteria sampel yang telah ditentukan. Distribusi frekuensi responden dapat dilihat pada Tabel 1.

Tabel 1. Karakteristik Responden Pasien Hipertensi Berdasarkan Jenis Kelamin, Umur, Pekerjaan, dan Pendidikan Terakhir

\begin{tabular}{llcc}
\hline $\begin{array}{c}\text { Karakteristik } \\
\text { Responden }\end{array}$ & \multicolumn{1}{c}{ Kriteria } & f & \% \\
\hline Jenis Kelamin & 1. Laki-laki & 29 & 49 \\
& 2. Perempuan & 30 & 51 \\
Umur & $40-50$ tahun & 32 & 54 \\
& $51-65$ tahun & 27 & 46 \\
Pekerjaan & 1. IRT & 15 & 25 \\
& 2. PNS & 12 & 20 \\
& 3. Wiraswasta & 10 & 17 \\
& 4. Swasta & 11 & 19 \\
\multirow{5}{*}{ Pendidikan } & 5. Lain-lain & 11 & 19 \\
Terakhir & 1. SD & 4 & 7 \\
& 2. SLTP & 10 & 17 \\
& 3. SMA & 30 & 51 \\
& 4. Perguruan Tinggi & 15 & 25 \\
\hline
\end{tabular}

Tabel 1 menunjukkan lebih dari separuh responden berjenis kelamin perempuan (51\%), lebih dari separuh responden berada pada usia 40-50 tahun (54\%), pekerjaan terbanyak adalah IRT (Ibu Rumah Tangga) (25\%), dan lebih dari separuh responden berpendidikan terakhir SMA $(51 \%)$.

Skala dukungan keluarga dan kepatuhan diukur dengan 20 poin pernyataan dengan rentang skor $20-80$, rentang minimum-maksimumnya adalah 20x1=20 sampai dengan $20 \times 4=80$. Sehingga luas jarak sebarannya adalah $80-20=60$. Dengan demikian setiap 
satuan devasi standarnya bernilai $\sigma=60 / 6=10$, dan mean teoritisnya adalah $\mu=20 \times 3=60$. Berdasarkan rumus tersebut akan diperoleh kategori-kategori skor dukungan keluarga yaitu: tinggi, sedang dan rendah.

Tabel 2. Distribusi Responden Berdasarkan Kategori Dukungan Keluarga

\begin{tabular}{lccc}
\hline $\begin{array}{l}\text { Dukungan } \\
\text { Keluarga }\end{array}$ & $\begin{array}{c}\text { Rentang } \\
\text { Nilai }\end{array}$ & $\mathbf{f}$ & $\mathbf{\%}$ \\
\hline Tinggi & $\geq 70$ & 7 & 12 \\
Sedang & $50-70$ & 32 & 54 \\
Rendah & $<50$ & 20 & 34 \\
Total & & $\mathbf{5 9}$ & $\mathbf{1 0 0}$ \\
\hline
\end{tabular}

Tabel 2 menunjukkan lebih dari separuh (54\%) responden mendapatkan dukungan keluarga dengan kriteria sedang.

Tabel 3. Distribusi Responden Berdasarkan Kategori Kepatuhan

\begin{tabular}{lccc}
\hline \multicolumn{1}{c}{ Kepatuhan } & $\begin{array}{c}\text { Rentang } \\
\text { Nilai }\end{array}$ & f & \% \\
\hline Tinggi & $\geq 70$ & 8 & 14 \\
Sedang & $50-70$ & 35 & 59 \\
Rendah & $<50$ & 16 & 27 \\
Total & & $\mathbf{5 9}$ & $\mathbf{1 0 0}$ \\
\hline
\end{tabular}

Tabel 3 menunjukkan lebih dari separuh (59\%) responden mempunyai kepatuhan dengan kriteria sedang.

Sebelum dilakukan analisa bivariat, terlebih dahulu dilakukan uji normalitas untuk menentukan uji hipotesis yang akan digunakan. Hasil uji normalitas adalah dukungan keluarganilai $p=0,000(p \leq 0,05)$ dan untuk kepatuhan nilai $p=0,001(p \leq 0,05)$. Kedua data memiliki nilai kemaknaan $\mathrm{p} \leq 0,05$ sehingga dapat disimpulkan data tidak berdistribusi normal maka uji hipotesis yang digunakan adalah uji korelasi Rank Spearman (r).

Data yang di analisis dengan uji korelasi Rank Spearman (r) didapatkan angka koefisien korelasi $(r)=0,786$ dengan nilai signifikansi 0,000, sehingga $\mathrm{Ha}$ diterima dan hubungan kedua variabel sangat signifikan. Sementara dari nilai koefisien (r) yaitu 0,786 berada di range 0,75-0,99, sehingga disimpulkan bahwa antara dukungan keluarga dengan kepatuhan mempunyai hubungan sangat kuat. Koefisien korelasi bertanda positif $(+)$, terdapat hubungan searah, dengan kata lain semakin tinggi dukungan keluarga maka semakin tinggi pula kepatuhan. Nilai dari koefisien determinan (KD) adalah sebesar $61,8 \%$, dapat disimpulkan bahwa dukungan keluarga berkontribusi sebesar $61,8 \%$ terhadap kepatuhan pada pasien hipertensi dan $38,2 \%$ dipengaruhi oleh faktor-faktor lainnya.

\section{Pembahasan}

Hasil penelitian menunjukkan bahwa terdapat hubungan yang bermakna $(\mathrm{p}=0,000)$, positif dan sangat kuat $(r=0,786)$ antara dukungan keluarga dengan kepatuhan pasien hipertensi. Artinya semakin tinggi dukungan keluarga maka akan semakin tinggi tingkat kepatuhan pasien hipertensi. Hasil penelitian ini juga menunjukkan bahwa dukungan keluarga memberi sumbangan sebesar $61,8 \%$ terhadap kepatuhan pada pasien hipertensi $\left(\mathrm{KD}=\mathrm{r}^{2}=61,8\right)$.

Penelitian ini sejalan dengan penelitian yang dilakukan oleh Olowookere, et al. (2015) yang menunjukkan bahwa pasien dengan dukungan keluarga tinggi lebih patuh dibandingkan dengan pasien dengan dukungan keluarga rendah. Penelitian lainnya yang dilakukan oleh Osamor (2015) juga membuktikan bahwa dukungan keluarga sangat terkait dengan kepatuhan pengobatan hipertensi.

Lebih lanjut Olowookere, et al. (2015) melaporkan bahwa $39 \%$ pasien tidak patuh terhadap terapi. Angka ini lebih rendah dibanding data WHO (2003) yang menyebutkan bahwa $50 \%-80 \%$ pasien hipertensi tidak patuh terhadap terapi. Sejalan dengan penelitian di atas, hasil penelitian pada Tabel 3 menunjukkan bahwa hanya sebagian kecil responden yang memiliki kepatuhan tinggi (14\%), sementara lebih dari sebagian (59\%) menunjukkan kepatuhan sedang, malah masih ada yang memiliki kepatuhan rendah (27\%). 
WHO (2003) menyebutkan bahwa ketidakpatuhan terhadap terapi merupakan salah satu penyebab tidak efektifnya pengobatan hipertensi. Sekitar $75 \%$ dari pasien yang tidak patuh terhadap terapi mengalami tekanan darah yang tidak terkontrol. Dampaknya adalah meningkatnya angka kematian terutama disebabkan karena komplikasi seperti gangguan jantung koroner.

Menurut Osamor (2015), penyakit kronis seperti hipertensi membutuhkan pengobatan seumur hidup. Hal ini merupakan tantangan bagi pasien dan keluarga agar dapat mempertahankan motivasi untuk mematuhi pengobatan selama bertahun-tahun. Salah satu cara untuk meningkatkan motivasi adalah melalui dukungan keluarga.

Menurut Wilson dan Ampey-Thornhill (2001), dukungan keluarga adalah bantuan atau pertolongan yang diberikan oleh anggota keluarga. Ketika keluarga berbagi masalahnya dengan sitem dukungan sosial maka saran dan bimbinggan akan diberikan kepada klien. Menciptakan lingkungan yang penuh kasih sayang, mengarahkan dan menemukan sumber perawatan serta memberikan bantuan finansial merupakan bentuk umum dari dukungan keluarga. Menurut Osamor (2015), dukungan sosial akan meningkatkan kesadaran untuk menggunakan pelayanan kesehatan yang merupakan salah satu komponen penting dari kepatuhan.

Penatalaksanaan penyakit kronik seperti hipertensi membutuhkan dukungan keluarga yang adekuat. Memperluas dukungan keluarga tidak hanya terbatas pada pasangan atau anggota keluarga yang lainnya tetapi juga melibatkan keluarga nuklir (jaringan sosial keluarga) sangat dibutuhkan (Wilson \& Ampey-Thornhill, 2001). Menurut Osamor (2015), perawat dapat membantu keluarga dalam mengeksplorasi penggunaan jaringan keluarga. Dukungan keluarga memungkinkan keluarga berfungsi dengan penuh kompetensi sehingga dapat meningkatkan adaptasi dan kesehatan keluarga.
Menurut WHO (2013) dukungan keluarga merupakan salah satu intervensi untuk meningkatkan kepatuhan pada pasien hipertensi. Sayangnya hasil penelitian pada tabel 2 menunjukkan bahwa hanya sebagian kecil responden yang memiliki dukungan keluarga tinggi (12\%), sementara lebih dari sebagian (54\%) menunjukkan kepatuhan sedang, malah masih ada yang memiliki kepatuhan rendah (34\%). Menurut Wilson dan Ampey-Thornhill (2001), dukungan sosial yang rendah akan memberikan pemecahan masalah yang sangat tidak memuaskan dalam keluarga.

Puskesmas sebagai fasilitas pelayanan kesehatan dasar perlu melakukan upaya-upaya untuk meningkatkan kepatuhan pasien hipertensi sehingga faktor risiko hipertensi dapat dikurangi atau dicegah (Kemenkes, 2012). Sayangnya beberapa program yang dilakukan puskesmas tidak memasukkan dukungan keluarga sebagai suatu upaya promosi kesehatan pada hipertensi. Menurut Olowookere, et.al. (2015), banyak penelitian telah melaporkan bahwa dukungan keluarga dapat meningkatkan kepatuhan terhadap terapi pada penyakit kronis. Temuan ini menekankan pentingnya mengidentifikasi dukungan keluarga pada saat dimulainya terapi hipertensi sampai selanjutnya.

Penelitian yang dilakukan Li, et al., (2015), dengan memberikan paket pengawasan berbasis anggota keluarga selama 1 bulan, kemudian memberikan pantauan terhadap keluarga tersebut selama 6-12 bulan, menunjukkan bahwa dukungan keluarga memberikan hasil yang signifikan terhadap terkontrolnya tekanan darah. Meskipun hasilnya tidak signifikan pada akhir sesi namun intervensi ini menunjukkan bahwa keluarga memiliki dampak positif terhadap kepatuhan pasien dalam terapi. Menurut Osamor (2015), dukungan keluarga perlu dipertimbangkan sebagai sebuah program untuk strategi promosi kesehatan penyakit kronis.

Hasil penelitian ini didapatkan 32 responden (54\%) mendapatkan dukungan keluarga dengan 
kategori sedang dan 7 responden (12\%) mendapatkan dukungan keluarga dengan kategori tinggi. Kemudian 35 responden (59\%) mempunyai kepatuhan dengan kategori sedang. Berdasarkan penelitian terlihat bahwa antara dukungan keluarga dengan kepatuhan mempunyai hubungan sangat kuat.

Tujuh responden yang mempunyai dukungan keluarga dengan kategori tinggi terdapat lima (71\%) yang memiliki kepatuhan dengan kategori sedang. Hal ini bisa terjadi karena adanya dukungan keluarga yang diberikan baik itu dukungan emosional, dukungan penghargaan, dukungan instrumental dan dukungan informasional dapat membuat penderita mengikuti ketentuan terapi yang telah ditetapkan petugas kesehatan. Dari 20 responden yang memiliki dukungan keluarga dengan kategori rendah, 16 orang memiliki kepatuhan dengan kategori rendah pula $(80 \%)$.

Hasil ini mendukung penelitian sebelumnya yang menyebutkan bahwa terapi akan lebih efektif dengan adanya dukungan keluarga. Gruber dan Haldeman (2009) menyebutkan bahwa nilai dalam keluarga merupakan sumber dukungan bagi anak yang mendapat terapi akibat obesitas. Demikian pula menurut pendapat Wright, Wilson, Griffin, dan Evans (2010), yang menyatakan bahwa dukungan orang tua memengaruhi remaja yang mengalami masalah dalam aktivitas.

Untuk kepatuhan minum obat dapat dilihat pada pernyataan kuesioner nomor 1 (75\%) yaitu responden selalu meminum obat sesuai dengan resep dan petunjuk dokter. Kepatuhan minum obat tersebut dipengaruhi oleh dukungan emosional yang didapatkan responden, terbukti dengan poin pernyataan kuesioner nomor 8 tentang kepedulian keluarga mengingatkan responden untuk minum obat secara teratur dijawab sering (45\%).

Kepatuhan menjalani diet dapat dilihat pada pernyataan kuesioner nomor 12 (68\%) responden jarang mengkonsumsi makanan yang di- awetkan. Kepatuhan menjalani diet ini berhubungan dengan dukungan informasional yang diberikan keluarga. Hal ini terlihat dari poin kuesioner dukungan keluarga nomor 3 yaitu keluarga sering memberi tahu responden makanan apa yang harus dihindari. Namun tidak begitu dengan dukungan informasional pada poin kuesioner nomor 14 yaitu keluarga jarang mengingatkan responden untuk tidak mengkonsumsi makanan siap saji. Kebutuhan informasi oleh penderita hipertensi sangat memengaruhi kepatuhannya menjalani diet.

Selanjutnya kepatuhan berolahraga dapat dilihat pada pernyataan kuesioner nomor 9 (70\%) responden sering menyempatkan untuk melakukan gerakan ringan selama 30-40 menit dalam sehari. Serta kepatuhan untuk mengelola stres dapat dilihat pada pernyataan kuesioner nomor $13(53 \%)$ responden sering menonton TV dengan keluarga untuk menenangkan pikiran. Olahraga dan mengelola stres ini dapat dilakukan dengan baik oleh responden dengan tingkat usia 40-50 tahun dengan kategori kepatuhan tinggi (63\%).

Dukungan instrumental seperti meminta pertolongan terlihat pada poin kuesioner nomor $10(59 \%)$ yaitu keluarga jarang menghindar jika responden meminta pertolongan, serta pada poin kuesioner nomor 19 (59\%) yaitu keluarga sering membelikan makanan untuk responden sesuai dengan aturan terapi. Dukungan penghargaan terlihat pada pernyataan kuesioner nomor 5 (63\%) yaitu keluarga sering memberi pujian kepada responden jika ada kemajuan kesehatan, dan pernyataan kuesioner nomor 17 (43\%) yaitu keluarga sering menasehati responden untuk patuh menjalani terapi.

Pada poin kuesioner nomor $3(59 \%)$ yaitu keluarga sering memberi tahu penderita hipertensi mengenai makanan apa saja yang harus dihindari. Namun dukungan informasional ini tidak begitu baik didapatkan oleh penderita hipertensi, terbukti dengan pernyataan kuesioner nomor $9(54 \%)$ keluarga sering tidak 
memberitahukan bahwa ada informasi mengenai penyuluhan kesehatan terkait hipertensi. Mungkin saja hal tersebut yang menyebabkan 32 responden (54\%) hanya mendapatkan dukungan keluarga dengan kategori sedang.

Untuk peneliti yang berminat melanjutkan penelitian ini dapat melakukan metode yang berbeda seperti pengembangan instrumen yang lebih baik lagi dan meneliti lebih lanjut mengenai dukungan informasional dalam kepatuhan menjalani terapi.

\section{Kesimpulan}

Berdasarkan hasil penelitian terdapat hubungan antara dukungan keluarga dengan kepatuhan pada pasien hipertensi dengan korelasi sangat kuat dan mempunyai arah positif (+) dan dukungan keluarga berkontribusi sebesar $61,8 \%$ terhadap kepatuhan pada pasien hipertensi.

Penelitian ini dapat dijadikan bahan pertimbangan dalam pemberian penyuluhan pada keluarga tentang pentingnya dukungan keluarga terutama dukungan informasional, salah satu contoh dengan mencarikan informasi penting mengenai hipertensi kepada penderita (PY, AW, TN).

\section{Referensi}

Almas, A., Hameed, B., \& Islam, M. (2007). Compliance to antihypertensive therapy. Diperoleh dari http://www.ncbi.nlm.nih.gov/ entrez/query.fcgi?tool=abstractplus\&db.

Departemen Kesehatan Indonesia. (2010). Profil kesehatan Indonesia 2010. Diperoleh dari http://www.depkes.go.id/

Gruber, K.J., \& Haldeman, L.A. (2009). Using the family to combat childhood and adult obesity. Prev Chronic Dis, 6 (3), A106.
Kementrian Kesehatan Republik Indonesia. (2012). Masalah hipertensi di Indonesia. Diperoleh dari www.depkes.go.id

Li, G., Hu, H.H., \& Aroo, T. (2015). The association of family social support, depression, anxiety and self-efficacy with specific hypertension self-care behaviors in Chinese Local Community. Journal of Human Hypertension, 29 (3),198-203.

Myers, T. (2015) Hypertension patient compliance. Sycamore Scholars. URI: http://hdl.handle. net/10484/12099

Olowookere, A.J., Olowookere, S.A., Talabi, A. O., Etonyeaku, A.C., Adeleke, O.E., \& Akinboboye, O.O. (2015). Perceived family support and factors influencing medication adherence among hypertensive patients attending a Nigerian tertiary hospital. Annals of Tropical Medicine and Public Health, 8 (6), 241.

Ong, K. L., Cheung, B. M., Man, Y. B., Lau, C. P., \& Lam, K. S. (2007). Prevalence, awareness, treatment, and control of hypertension among United States adults 1999-2004. Hypertension, 49(1), 69-75.

Osamor, P.E. (2015). Social support and management of hypertension in South-Nigeria. Cardiovascular Journal of Africa, 26 (1), 2933.

Pos Kota News. (2012). Penderita Hipertensi Tergolong Tinggi di Indonesia. Diperoleh dari http://www.poskotanews.com/2012/09/08/pen derita-hipertensi-tergolong-tinggi-di-indonesia/

Wilson, D. K., \& Ampey-Thornhill, G. (2001). The role of gender and family support on dietary compliance in an African American adolescent hypertension prevention study. Annals of Behavioral Medicine, 23,(1), 59-67.

World Health Organization. (2003). Adherence to long-term therapies: evidence for action. Diperoleh dari dari http://www. who.int/chp/knowledge/publications/adherence _report/en/ 
(2003). International Society of Hypertension (ISH) statement on management of hypertension. Diperoleh dari www.who.int/cardiovascular_diseases/.../hyper tension_guidelines.pdf

(2007). The World Health Report 2007. Diperoleh dari http://www.who. int/whr/2007/en/index.html

Wright, M.S., Wilson, D.K., Griffin, S., \& Evans, A. (2010). A qualitative study of parental modeling and social support for physical activity in underserved adolescents. Health Education Research, 25 (2), 224-232. 